\title{
Neutral glycosphingolipid content of ovine milk
}

\author{
L. Zancada, ${ }^{*}$ F. Sánchez-Juanes, ${ }^{*}$ J. M. Alonso,† and P. Hueso*1 \\ *Departamento de Bioquímica y Biología Molecular, Facultad de Biología, Universidad de Salamanca, 37007 Salamanca, Spain \\ †Departamento de Bioquímica, Biología Molecular y Fisiología, Escuela Universitaria de Ingenierías Agrarias de Soria, Universidad de Valladolid, \\ 42003 Soria, Spain
}

\section{ABSTRACT}

Milk glycosphingolipids (GSL) have been reported to participate in the newborn's defense against pathogens. Taking this into account, in this study we determined the neutral GSL content of ovine milk, including its fatty acid profile. Its role in bacterial adhesion was also addressed by immunodetection of separate GSL in a high-performance thin-layer chromatography overlay assay. Ovine milk has a neutral GSL pattern similar to human milk and includes lactosylceramide (LacCer; $45.7 \%$ ), monohexosylceramide (glucosylceramide and galactosylceramide, $31.2 \%$ ), globotriaosylceramide (Gb3; 19.1\%), and globotetraosylceramide (Gb4; 3.5\%). Globotriaosylceramide and Gb4 are present in human but not bovine milk. Neutral GSL contained C23:0 and C24:0 as the most abundant fatty acids, a finding consistent with its high content of very long chain fatty acids (longer than C20). Most fatty acids were saturated and had a low content of polyunsaturated fatty acids. Bovine enterotoxigenic Escherichia coli strains bound strongly to LacCer and showed a weak binding to monohexosylceramide. The K99 strain also bound strongly to Gb3, and F41 to Gb4. Lactosylceramide, monohexosylceramide, and Gb3 were also observed to bind to human uropathogenic E. coli strains. The results reported here show the ability of neutral GSL in ovine milk to bind to E. coli strains. These compounds could be used as an alternative and available source to supplement infant or bovine formulas with a view to preventing bacterial infections.

Key words: bacterial adhesion, glycosphingolipid, ovine milk

\section{INTRODUCTION}

The general composition (fat, total protein, casein, and so on) of ewe milk has been extensively studied. However, minor components such as glycoconjugates have been only partly determined in individual studies (Alais and Jollès, 1967; Morrisey, 1973; Puente et al.,

Received June 10, 2009.

Accepted September 30, 2009.

${ }^{1}$ Corresponding author: phueso@usal.es
1995). In those studies, neither the neutral glycosphingolipid (GSL) content nor the fatty acid content of GSL were considered.

Neutral GSL are complex membrane lipids with a hydrophobic ceramide moiety composed of a fatty acid tail linked by an amide bond to a sphingoid base (sphingosine) inserted in the outer leaflet of the glycerophospholipid bilayer, and a hydrophilic carbohydrate moiety that protrudes from the membrane surface (Sonnino et al., 2009). They are important constituents of the milk fat globule membrane, which contains 60 to $70 \%$ of the milk content of these compounds (Keenan and Patton, 1995; Dewettinck et al., 2008). The biological significance of milk glycoconjugates, including neutral GSL, remains unclear. When ingested, GSL reach the gastrointestinal tract, where they could influence the functional development of the neonatal intestine, the absorption of nutrients, and the postnatal development of the intestinal immune system (gut-associated lymphoid system; Dai and Walker, 1999; Rueda, 2007). They are also digested in the small intestine and colon, affording ceramide and sphingosine, which are taken up by intestinal cells and which participate as bioactive molecules in cell-signaling pathways (Vesper et al., 1999; Graves et al., 2007).

Milk contains several protective factors against pathogens, the most important being immunoglobulins. However, other nonimmunological components (lysozyme, lactoferrin, free fatty acids, monoglycerides, glycoconjugates, and others), defined as an innate immune system of human milk, have also been described (Newburg, 2005). In this sense, GSL also could exert a defensive role, acting as false soluble receptors for microorganisms and microbial toxins (Newburg, 1996; Newburg et al., 2005). Bacterial adhesins recognize the carbohydrate moiety on glycoconjugates. However, the ceramide composition seems to affect the sugar conformation by modulating the presentation, or accessibility, or both, of the binding epitope; hence, it modifies receptor recognition, explaining the relevance of the hydrophobic moiety of glycoconjugates in these cellular events (Kiarash et al., 1994; Teneberg et al., 1994; Zaas et al., 2005). 
Bearing this in mind, the aim of this work was to study the neutral GSL content of ewe milk, including the determination of the fatty acid composition of GSL. The role of neutral GSL in the defense of newborns against pathogens was also addressed by studying bacterial binding to these compounds.

\section{MATERIALS AND METHODS}

\section{Milk Samples}

Fresh, raw bulk-tank ewe milk samples from 3 consecutive days were obtained from the Sociedad Cooperativa Ganadera de Lácteos y Derivados (Cogalad, Valderrodrigo, Salamanca, Spain) in the month of November. Ewes were mainly of the Spanish Assaf breed and Assaf crossed with other breeds (90\%). The milk was cooled by the supplier and transported in an insulated container to the laboratory. Samples were immediately frozen at $-20^{\circ} \mathrm{C}$, lyophilized, and exhaustively mixed to provide a homogeneous concentration of the different milk components in the sample.

\section{Materials}

Resorcinol, orcinol, and $\alpha$-galactosidase from green coffee beans, and $\beta$ - $N$-acetylglucosaminidase from jack beans were purchased from Sigma (St. Louis, MO). Silica gel 60 high-performance thin-layer chromatography (HPTLC) plates, silicic acid, hexane, and isooctane were from Merck (Darmstadt, Germany). Phospray reagent, methanol-HCl reagent, and Supelco 37 fatty acid methyl ester mixture were obtained from Supelco Inc. (Bellefonte, PA). Diethylether, petroleum ether, and ethanol were from Panreac (Barcelona, Spain). Chloroform, methanol, and acetone were glass-distilled at our laboratory. A neutral GSL mixture containing galactosylceramide (GalCer), lactosylceramide (LacCer), globotriaosylceramide (Gb3), and globotetraosylceramide or globoside (Gb4) was from Larodan Fine Chemicals (Malmö, Sweden).

Rabbit anti-Escherichia coli polyclonal antibody was from Dako (Copenhagen, Denmark) and Abcam (Cambridge, UK). Mouse anti-bovine galactocerebroside was from Europa Bioproducts Ltd. (Cambridge, UK). Mouse polyvalent biotin-conjugated IgG, IgM, IgA, ExtrAvidin-alkaline phosphatase, and FAST-BCIP/ NBT (5-bromo-4-chloro-3-indolyl phosphate/nitro blue tetrazolium) were from Sigma. Polyisobutyl methacrylate was from Aldrich Chemical Co. (Milwaukee, WI). Bovine serum albumin was provided by Fluka (Buchs, Switzerland). Mueller-Hinton broth was from Difco (Detroit, MI), and Isovitale X was from Becton Dickinson (Cockeysville, MD).

\section{Analytical Procedures}

Total lipids were determined with the Röse-Gottlieb method (IDF, 1996). Briefly, lyophilized milk samples $(1 \mathrm{~g})$ were reconstituted in water according to their original water content. Next, $1.5 \mathrm{~mL}$ of an aqueous ammonia solution $\left(25 \%\right.$ in $\left.\mathrm{NH}_{3}\right)$ was added to $10 \mathrm{~g}$ of reconstituted milk and mixed; then, $10 \mathrm{~mL}$ of $96 \%$ ethanol was added and mixed; finally, $25 \mathrm{~mL}$ of diethylether (stabilized with $6 \mathrm{ppm}$ of butylated hydroxytoluene) was added. The mixture was then vigorously shaken for $5 \mathrm{~min}$. After this, $25 \mathrm{~mL}$ of petroleum ether was added and the mixture was shaken vigorously for 10 min. Samples were centrifuged at $1,100 \times g$ for $10 \mathrm{~min}$ at $4^{\circ} \mathrm{C}$. The lower phase was reextracted with diethylether, ethanol, and petroleum ether as described above. The extraction process was repeated a third time with the new lower phase. The upper phases containing lipid were evaporated to dryness in a rotary evaporator and heated for $1 \mathrm{~h}$ at $100^{\circ} \mathrm{C}$ until complete elimination of solvents. After cooling, the amount of lipids was measured gravimetrically.

\section{Extraction, Purification, and Identification of Neutral GSL}

Neutral GSL were prepared as described previously (Sánchez-Juanes et al., 2009). Briefly, neutral lipids were extracted twice with 10 volumes of cold acetone. The solid residue was successively extracted with 10 volumes each of chloroform:methanol (2:1, 1:2, and 1:1; $\mathrm{vol} / \mathrm{vol}$ ) and the combined extracts were subjected to a Folch partition procedure. Neutral GSL were isolated from the lower phase of the Folch partition as previously reported (Newburg and Chaturvedi, 1992), with some modifications. The lower phase was evaporated to dryness and neutral GSL were purified by silicic acid column chromatography. The sample (dissolved in $1 \mathrm{~mL}$ of chloroform) was loaded onto a column containing 5 $\mathrm{g}$ of silicic acid in chloroform. Neutral GSL were eluted with $50 \mathrm{~mL}$ of acetone:methanol $(9: 1, \mathrm{vol} / \mathrm{vol})$ and evaporated to dryness to obtain a purified neutral GSL fraction. This fraction was deacylated by mild alkaline hydrolysis in $3 \mathrm{~mL}$ of $0.6 \mathrm{M} \mathrm{NaOH}$ in methanol plus $3 \mathrm{~mL}$ of chloroform for $1 \mathrm{~h}$ at room temperature. The reaction was stopped with $4.5 \mathrm{~mL}$ of $0.4 \mathrm{M} \mathrm{HCl}$, and 3 $\mathrm{mL}$ of methanol and $9 \mathrm{~mL}$ of chloroform were added. The mixture was shaken for $10 \mathrm{~min}$ and separated into 2 phases. After removing the upper phase, $3 \mathrm{~mL}$ of chloroform:methanol:water $(3: 48: 47, \mathrm{vol} / \mathrm{vol} / \mathrm{vol})$ was added to the lower phase, the mixture was shaken for $10 \mathrm{~min}$, and the process was repeated with the lower phase. Remaining hydrolysis products were eliminated 
with a repeat silicic acid chromatography, as described above.

The purification of neutral GSL was followed by HPTLC. Replicate plates were developed with resorcinol (for gangliosides), orcinol (for neutral GSL), and Phospray (for phospholipids).

Neutral GSL were identified by comigration with authentic standards on glass-backed HPTLC plates [solvent system, chloroform:methanol:water (60:35:8, $\mathrm{vol} / \mathrm{vol} / \mathrm{vol}$ )] and were quantified by scanning densitometry at $515 \mathrm{~nm}$ in a dual-wavelength densitometer (Shimadzu CS 9000, Kyoto, Japan) after separation by HPTLC and development with orcinol reagent (Rosengren et al., 1987). Values were calculated from standard curves of glucosylceramide (GlcCer) and LacCer.

Immunostaining on aluminum-backed silica gel 60 HPTLC plates was performed as previously reported (Martín et al., 2001) to identify GalCer in the samples. An anti-bovine galactocerebroside monoclonal antibody was used. Also, Gb3 and Gb4 were identified by enzymatic digestion by glycosidases and analysis of the products (Dasgupta et al., 1996). Neutral GSL $(20 \mu \mathrm{g})$ were subjected to $\alpha$-galactosidase ( $50 \mathrm{mM}$ phosphatecitrate buffer, $\mathrm{pH} 6.5$, in a final volume of $200 \mu \mathrm{L}$ ) or $\beta$ - $N$-acetylglucosaminidase $(50 \mathrm{~m} M$ citrate buffer containing $0.1 \%$ taurodeoxycholate, $\mathrm{pH} 4.2$, in a final volume of $250 \mu \mathrm{L}$ ) digestion for $24 \mathrm{~h}$ at $37^{\circ} \mathrm{C}$. Reactions were stopped with 4 volumes of chloroform:methanol (2:1) to obtain a biphasic system. The lower phase was washed twice with chloroform:methanol: $\mathrm{H}_{2} \mathrm{O}$ (3:48:47, $\mathrm{vol} / \mathrm{vol} / \mathrm{vol}$ ), evaporated to dryness, and dissolved in chloroform:methanol (2:1). The GSL contained in the lower phase were spotted onto an HPTLC plate and compared with the original GSL not subjected to enzymatic digestion.

\section{Determination of the Fatty Acid Content of Neutral GSL}

Fatty acid contents were studied by gas chromatography-mass spectrometry at the Mass Spectrometry Service of the University of Salamanca (Spain). Neutral GSL $(50 \mu \mathrm{g})$ were evaporated to dryness under a nitrogen stream. Then, $0.5 \mathrm{M}$ methanolic $\mathrm{HCl}(400 \mu \mathrm{L})$ was added and the sealed tubes were incubated for 20 $\mathrm{h}$ at $80^{\circ} \mathrm{C}$. Fatty acid methyl ester were then extracted twice with $1.5 \mathrm{~mL}$ of hexane and evaporated to dryness under a nitrogen stream. Fatty acid methyl ester were taken up in isooctane and injected into a gas chromatograph apparatus (Shimadzu GC 17A) equipped with a Tracsil TR-WAX capillary column $(30 \mathrm{~m} \times 0.25 \mathrm{~mm} \times$ $0.25 \mu \mathrm{m}$; Teknokroma, Barcelona, Spain). The injector temperature was $210^{\circ} \mathrm{C}$ and the detector temperature was $240^{\circ} \mathrm{C}$. The initial temperature was $115^{\circ} \mathrm{C}$ for 5 min. The temperature was raised to $190^{\circ} \mathrm{C}$ at a rate of $10^{\circ} \mathrm{C} / \mathrm{min}$ and then to $230^{\circ} \mathrm{C}$ at a rate of $2^{\circ} \mathrm{C} / \mathrm{min}$. This final temperature was then held for 20 min. Peaks were identified by their characteristic mass spectra in a coupled Shimadzu MS QP 5000 mass spectrometer. Analysis was performed in electron-impact mode (ionization energy $=70 \mathrm{eV}$; source temperature $=150^{\circ} \mathrm{C}$ ). The carrier gas was helium. A calibration curve was obtained under the same experimental conditions with a standard fatty acid methyl ester mixture, Supelco 37, to correct differences in the detector response. Fatty acids were expressed as percentages of total fatty acids (\% wt).

\section{Bacterial Strains and Media}

Four enterotoxigenic E. coli strains (ETEC) and 2 uropathogenic E. coli (UPEC) strains isolated from diarrheic calves and humans, respectively, were provided by Jorge Blanco from the Reference Laboratory of Escherichia coli (Lugo, Spain). The characteristics of each ETEC strain were K99-12 (serogroup O8; adhesin K99), F41-15 (serogroup O20; adhesin F41), K99-4 (serogroup O101; adhesin K99 + F41), and CCB1 (serogroup O101; adhesin F17/Att 25). The characteristics of the UPEC strains were FVL3 (serogroup O6:H1; adhesin P) and FVL25 (serogroup O2: H1; adhesin P-like). Bacteria were grown in Mueller-Hinton broth for 3 to $5 \mathrm{~d}$ at $37^{\circ} \mathrm{C}$. When grown in this medium, the bacteria lacked fimbriae. For fimbria expression, bacteria were grown on Minca agar containing Isovitale $\mathrm{X}$ at $37^{\circ} \mathrm{C}$ for $16 \mathrm{~h}$ (ETEC strains; Guineé et al., 1977) and on CFA-agar plates at $37^{\circ} \mathrm{C}$ overnight (UPEC strains; Evans and Evans, 1978). Bacteria were also grown at $18^{\circ} \mathrm{C}$ for negative controls of fimbria expression.

\section{Adhesion of Bacteria to GSL on HPTLC Plates}

The adhesion of the bacteria to GSL in HPTLC was examined by immunodetection (Karlsson and Stromberg, 1987). Briefly, neutral GSL $(2-4 \mu \mathrm{g}$ in each lane) were separated in duplicate on aluminum-backed HPTLC plates with an appropriate solvent system, in this case chloroform:methanol:water (60:35:8, by vol). One half of the plate was developed with orcinol reagent. For adhesion, the other half was dipped in $0.1 \%$ polyisobutyl methacrylate in hexane for $75 \mathrm{~s}$ and allowed to dry. Once dried, it was soaked in $2 \% \mathrm{BSA}$ containing $150 \mathrm{mM} \mathrm{NaCl}, 5 \mathrm{~m} M$ PBS (pH 7.4; blocking buffer) for $1 \mathrm{~h}$. The plate was covered with the bacterial suspension $\left(10 \mathrm{~mL}, 1 \times 10^{8} \mathrm{cfu} / \mathrm{mL}\right)$ and incubated for $2 \mathrm{~h}$ at $37^{\circ} \mathrm{C}$ in a humid chamber. The plate was then thoroughly washed (4 times, 5 min each) with PBS and incubated with the anti- $E$. coli polyclonal antibody at 
1:25 in the blocking buffer for $1 \mathrm{~h}$ at room temperature. Biotinylated anti-rabbit IgG and streptavidin-alkaline phosphatase conjugate were added successively $(1: 1,000$ in the blocking buffer) over $1 \mathrm{~h}$ at room temperature before developing with the FAST-BCIP substrate.

\section{RESULTS AND DISCUSSION}

Bulk-tank milk was used to obtain a representative ewe milk GSL profile, regardless of the stage of lactation, parity, and so on. Prior to the determination of the neutral GSL content of the milk, several general parameters were determined. The total solids content was found to be $19.1 \%$ (wt/vol), fat content was $7.5 \%$ (wt/vol), and protein content was $5.5 \%$ (wt/vol; value provided by the milk supplier, Cogalad).

Ovine milk has a neutral GSL content of $9.7 \pm 1.2$ $\mathrm{mg} / \mathrm{L}$ of fresh milk (the value is the mean of 3 independent determinations). This value is lower than that reported for bovine milk $[17.8 \mathrm{mg} / \mathrm{L}$ (Christie et al., 1987) or $21.0 \mathrm{mg} / \mathrm{L}$ (Newburg and Chaturvedi, 1992)] but higher than that corresponding to human milk [4.4 $\mathrm{mg} / \mathrm{L}$ (Newburg and Chaturvedi, 1992)]. The reasons for these differences are unclear. Regarding fat contents, ovine milk contains more fat than cow and human milk, but less neutral GSL than cow milk and more neutral GSL than human milk. Because ovine milk fat globules are smaller than those of cow milk $(3.30 \mu \mathrm{m}$ vs. 4.55 $\mu \mathrm{m}$, respectively; Anifantakis, 1986), the size of the fat globules could be considered. However, no differences in the phospholipid (PL) profile between milk fat globule membrane extracted from small and large milk fat globule fractions (Fauquant et al., 2007) and in the fatty acid composition of the PL from the milk fat globule membrane of small and large bovine milk fat globules (Fauquant et al., 2005) have been found. Perhaps the fat content and globule size are not determinant regarding the neutral GSL content. Regarding the neutral GSL pattern (Figure 1), ovine milk contains 4 different individual species [termed NG1 to NG4 according to their mobility on HPTLC plates (increasing polarity)] that appeared as 2 bands because of the heterogeneity of the ceramide moiety, as confirmed by the analysis of their fatty acid contents (see below). These individual GSL were identified by comigration with a standard reference panel. Species NG2, NG3, and NG4 comigrated with LacCer, Gb3, and Gb4, respectively. Species NG1 comigrated with both GlcCer and GalCer standards and reacted with the antigalactocerebroside monoclonal antibody that recognizes GalCer. It appears that NG1 would be a mixture of GlcCer and GalCer, the former being the main component. Also, Gb3 and Gb4 were identified by glycosidase digestion and analysis of the hydrolysis products by HPTLC.
Samples were hydrolyzed with $\alpha$-galactosidase, which removed the terminal $\alpha 1-4$ galactose residue of Gb3, thus giving rise to the disappearance of Gb3, or with $\beta$ - $N$-acetylglucosaminidase, which removed the terminal 31-3 N-acetylgalactosamine residue of Gb4, thus leading to the disappearance of Gb4. Samples before and after glycosidase treatment were compared by HPTLC to examine the disappearance of Gb3 or Gb4. All these glycolipids belong to the globo-series, which is initiated by the action of Gb3 synthase on LacCer. This neutral GSL profile is qualitatively similar to that of human milk because it also includes high amounts of Gb3 and Gb4, although differences in GSL percentages between human and ovine milk were found. Species NG2 accounted for $45.7 \%$ of the total neutral GSL (values are means of 3 determinations), followed by NG1 (31.2\%), NG3 (19.1\%), and NG4 (3.5\%). Human milk contains $74.2 \%$ of monohexosylceramide ( $\mathrm{GalCer}=88 \%$ and GlcCer $=12 \%$ of total monohexosylceramide), $21.1 \%$ of LacCer, $2.8 \%$ of Gb3, and 2.1\% of Gb4 (Newburg and Chaturvedi, 1992). Regarding Gb3, human milk contains $130 \mu \mathrm{g} / \mathrm{L}$ whereas ovine milk has $1.8 \mathrm{mg} / \mathrm{L}$. By contrast, bovine milk contains only GlcCer (35-37\%) and LacCer (63-65\%), with no complex neutral GSL such as Gb3 and Gb4 (Newburg and Chaturvedi, 1992; Sánchez-Juanes et al., 2009). However, very low, but still measurable, levels of Gb3 have been found in an individual bovine milk sample (Newburg and Chaturvedi, 1992). Densitometric analysis revealed that the upper band of individual GSL fractions from NG1 to NG3 accounted for 60 to $70 \%$ of the total individual GSL. Species NG4 showed an almost equal ratio of upper and lower bands (50-55 and $45-50 \%$, respectively). The similarity of the neutral GSL profiles of human and ewe milk and the differences in these profiles between bovine and ovine milk are striking. Furthermore, the reason for the high content of complex neutral GSL, namely Gb3 and Gb4, of ovine milk as compared with milk from other ruminants remains unclear.

The fatty acid content of the neutral GSL was determined by gas chromatography-mass spectrometry. The results are shown in Table 1. Figure 2 shows the fatty acid profile of neutral GSL. Two very long chain fatty acids, C23:0 and C24:0, were the most abundant fatty acids in neutral GSL, followed by C16:0. This is consistent with the high content of very long chain fatty acids (58\%). A low content of medium-chain fatty acids $(3.5 \%)$ was also found. Characteristically, most fatty acids were saturated $(88 \%)$, with a very low content of polyunsaturated fatty acids (1.7\%). This fatty acid profile is very different from that reported for neutral GSL in cow milk, which contain only 18 to $24 \%$ of very long chain fatty acids but a high content of long-chain fatty acids (68-73\%; Morrison et al., 1965; Sánchez-Juanes 
A

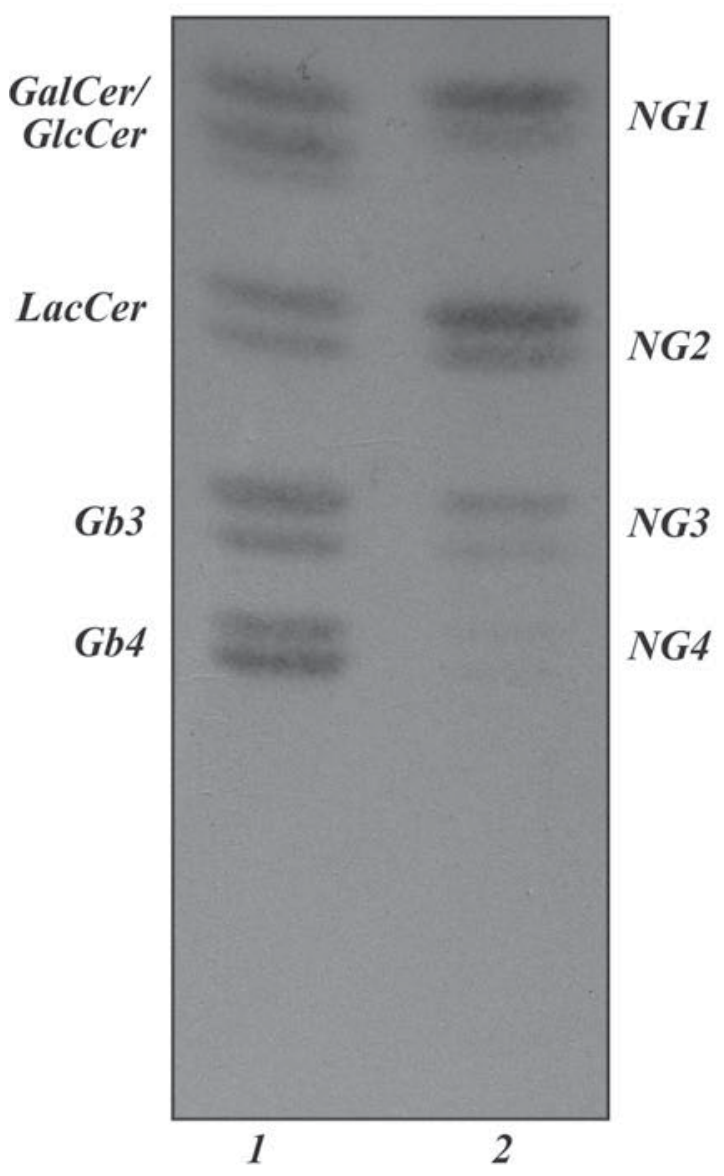

B

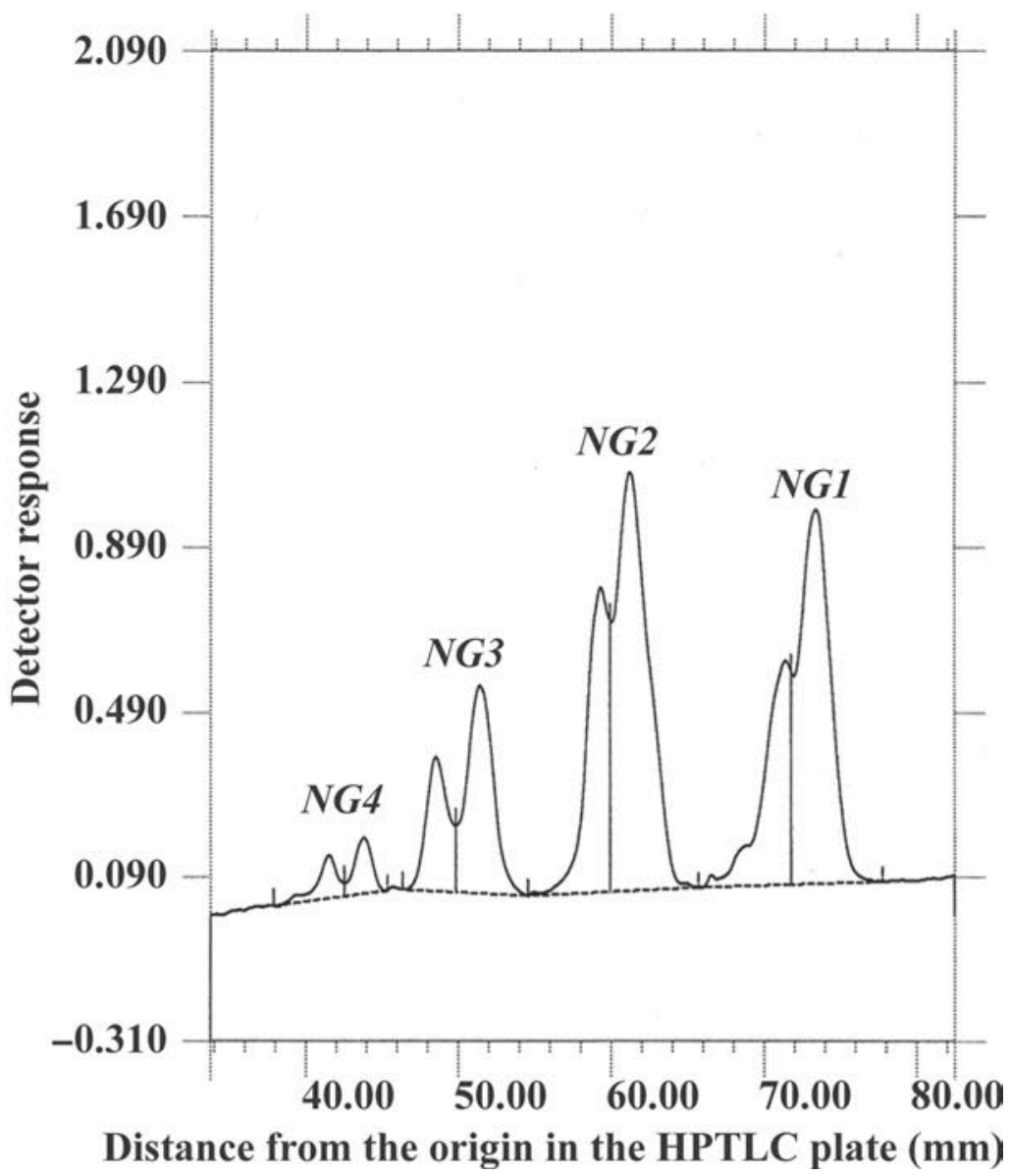

Figure 1. Ovine milk neutral glycosphingolipids. A) High-performance thin-layer chromatography (HPTLC) separation of neutral glycosphingolipids: 1 = neutral glycosphingolipid standard mixture; $2=$ ovine milk neutral glycosphingolipids. B) Densitometric analysis of an HPTLC plate.

et al., 2009). Fatty acids from neutral GSL in ovine milk are more saturated (88\%) that those from cow milk (75-77\%; Morrison et al., 1965; Sánchez-Juanes et al., 2009).

Purified neutral GSL from ovine milk were separated by HPTLC as described in the Materials and Methods section, and the adhesion of bacteria was examined by immunodetection. Besides the experimental work with antigen-defined and laboratory-adapted bacterial strains, it has previously been suggested (Isaacs, 2005) that bacterial adhesion assays must also be carried out with clinical bacterial isolates because the latter may have different binding specificities to the former. In this sense, our bacteria were strains isolated from infants and calves and were typified by serogroup and the presence of certain adhesions; however, other adherent molecules that could also be responsible for adhesion were probably present on their surfaces, such as type 1 pili (mannose-specific type 1 adhesins), mucins, IgA, or IgM. As shown in Figure 3, all bovine ETEC strains assayed showed strong binding to NG2 (LacCer) and weak binding to NG1. This result is similar to that previously found for bovine milk (Martín et al., 2003; Sánchez-Juanes et al., 2009), also with strong binding to LacCer and no binding to GlcCer. Both those research groups reported that ETEC strains bound to neutral GSL from whole milk more strongly than those from milk fat globule membranes. Neutral GSL in whole milk are located mainly in the milk fat globule membranes but also in the skim milk membranes of the whey phase. Even though bacterial adhesins recognize the carbohydrate moiety on glycolipids, the lipophilic part has also proved to be quite important, and a ceramide with unsaturated and short-chain fatty acids (as in neutral GSL in whole milk) seems to favor adhesion more than a ceramide with long-chain and saturated fatty acids (as in neutral GSL in milk fat globule membrane). Because neutral GSL from ovine 


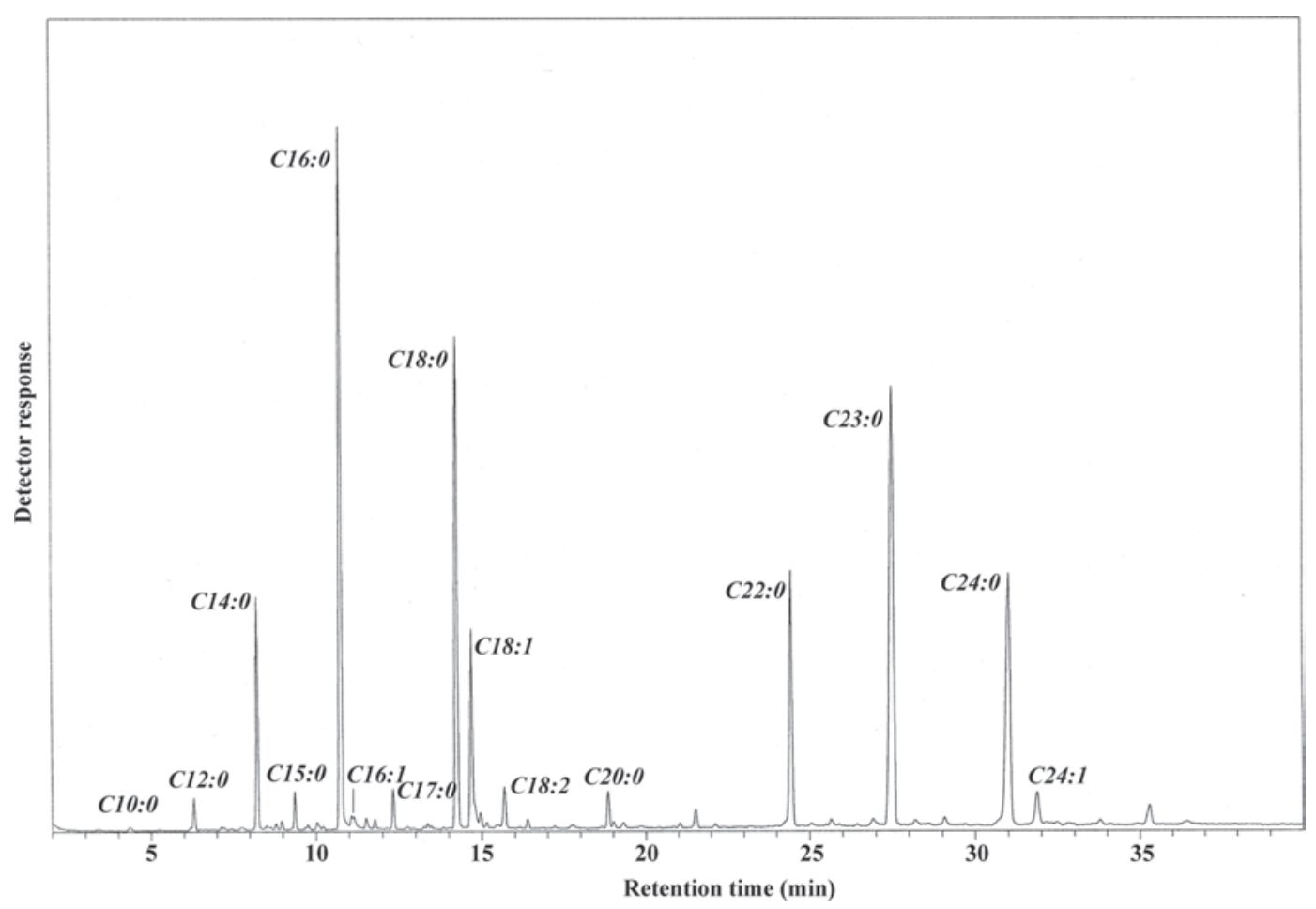

Figure 2. Gas chromatogram profile of fatty acid methyl esters from ovine milk neutral glycosphingolipids.

milk have a ceramide with a high content of saturated $(88 \%)$ and very long chain (59\%) fatty acids, binding would probably not be favored. However, we observed a high degree of binding. Furthermore, K99 also bound

Table 1. Fatty acid content (\% wt) of neutral glycosphingolipids ${ }^{1}$

\begin{tabular}{lr}
\hline Fatty acid & \multicolumn{1}{c}{$\%$} \\
\hline C10:0 & $0.2 \pm 0.0$ \\
C12:0 & $0.3 \pm 0.1$ \\
C14:0 & $2.6 \pm 0.3$ \\
C15:0 $16: 0$ & $0.4 \pm 0.1$ \\
C16:1 & $17.4 \pm 1.1$ \\
C17:0 & $0.3 \pm 0.1$ \\
C18:0 $18: 1$ & $0.5 \pm 0.2$ \\
C18:2 & $9.9 \pm 2.2$ \\
C20:0 & $7.6 \pm 2.2$ \\
C22:0 & $1.7 \pm 1.0$ \\
C23:0 & $0.7 \pm 0.2$ \\
C24:0 & $9.8 \pm 1.5$ \\
C24:1 & $28.2 \pm 2.5$ \\
SFA & $17.6 \pm 0.6$ \\
MUFA & $3.0 \pm 0.9$ \\
PUFA & $87.6 \pm 1.6$ \\
MCFA & $10.9 \pm 1.0$ \\
LCFA & $1.7 \pm 1.0$ \\
VLCFA & $3.5 \pm 0.1$ \\
\hline
\end{tabular}

${ }^{1}$ Values are means $\pm \mathrm{SD}, \mathrm{n}=3$.

${ }^{2} \mathrm{SFA}=$ saturated fatty acids; MUFA = monounsaturated fatty acids: PUFA = polyunsaturated fatty acids; $\mathrm{MCFA}=$ medium-chain fatty acids $(\mathrm{C} 10-\mathrm{C} 15)$; LCFA = long-chain fatty acids (C16-C20); VLCFA $=$ very long chain fatty acids $(\mathrm{C} 22-\mathrm{C} 24)$. strongly to NG3 (Gb3), the binding of other strains being weak. F41 showed strong binding to the minor component NG4 (Gb4). Because F41 showed a high affinity for $\mathrm{N}$-acetylgalactosamine, the terminal sugar of NG4, this was probably the reason for the binding of F41 to NG4. Human UPEC strains also bound to NG1, NG2, and NG3; Gb3 (NG3) and Gb4 (NG4) contain the galactose $\alpha 1-4$ galactose structure that acts as the receptor for adhesins of pathogenic E. coli and as the receptor for toxins.

It is well known that LacCer binds specifically to several pathogenic bacteria (Karlsson, 1989), including different strains of $E$. coli. However, it has also been reported that ETEC K99 or P-fimbriae strains do not bind to LacCer (Bock et al., 1985; Teneberg et al., 1994). Described as a second-step receptor for many bacteria (Karlsson, 1989), LacCer is a bilayerclose short glycolipid and the binding of bacteria to this receptor on epithelial cells is probably not favored; in contrast, it would be very available in an HPTLC overlay assay. In this sense, milk LacCer could be important as an available soluble receptor for bacteria in the gut, participating in the blocking of pathogens. However, although minimal amounts of GSL were used in the binding experiments, the detection of nonspecific binding to a very abundant GSL cannot be discarded.

Furthermore, Gb3, also called $\mathrm{P}^{\mathrm{k}}$ antigen or CD77, is a known receptor of verotoxins [e.g., Shiga toxin 


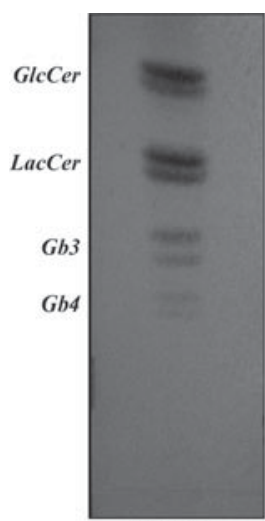

Standard

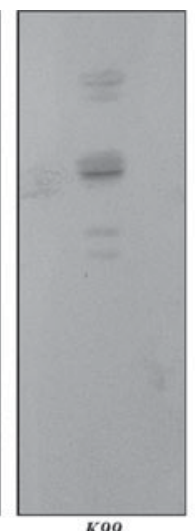

K99

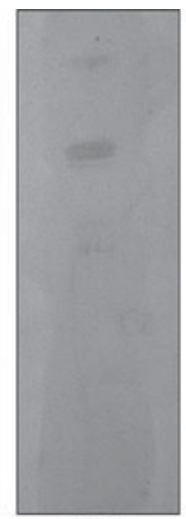

F41

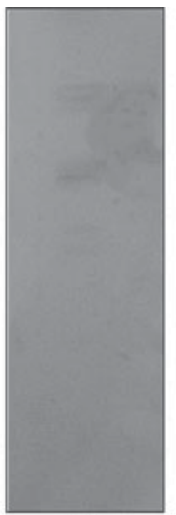

FK

Bacterial strain

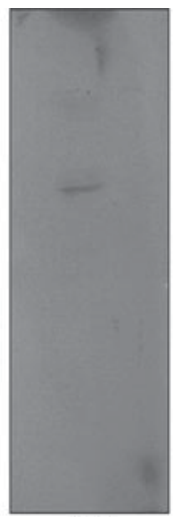

Att25

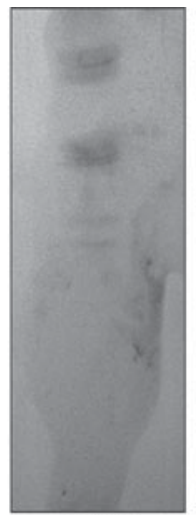

FVL25

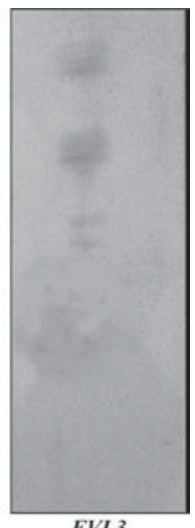

FVL3

Figure 3. Adhesion of bacteria (Escherichia coli strains) to neutral glycosphingolipids separated by high-performance thin-layer chromatography. Standard chemical detection of neutral glycosphingolipids from ovine milk with orcinol reagent. Immunostaining was carried out with an anti-E. coli polyclonal antibody. GlcCer = galactosylceramide; LacCer = lactosylceramide; Gb3 = globotriaosylceramide; Gb4 = globotetraosylceramide.

and Shiga-like toxins (Newburg et al., 1992)] that has been localized in uroepithelial cells and that plays a direct role in the entry of toxins into the cell (Keusch et al., 2000). It has also been reported that human vascular endothelial cells that accumulate Gb3 have an augmented sensitivity to Shiga toxin (Schweppe et al., 2008). Of special interest is the protection provided by human milk against Shigella infection based on the presence of Gb3 (Newburg et al., 1992). Here, Gb3 was biologically active and bound to bovine ETEC K99 and human UPEC (FVL 25 and FVL3). These results are in accordance with the notion that milk glycoconjugates are important as pathogenic adhesion inhibitors because of their polyvalence (Rueda, 2007).

Negative controls were carried out with bacteria grown at $18^{\circ} \mathrm{C}$ that did not express fimbriae. Under these conditions, the bacteria showed a very weak adhesion to GSL, probably because of the presence of other adherent molecules.

In light of these results, it appears that neutral GSL from ovine milk could participate in the blocking of human uropathogenic and bovine enteropathogenic bacteria. In this sense, ovine milk could be an important source of Gb3 for use as a false soluble receptor for Shiga toxins in the gastrointestinal tract, thus preventing bacterial infection.

\section{CONCLUSIONS}

Ovine milk has a high content of complex neutral GSL, such as Gb3 and Gb4, which are very abundant in human milk but not in bovine milk and which are able to bind to some ETEC and UPEC strains. Their fatty acid profile is also different from that of neutral GSL in bovine milk.

\section{ACKNOWLEDGMENTS}

This work was supported by grants from the Programa de Apoyo a Proyectos de Investigación de la Junta de Castilla y León, España (SA 019/04 and SA 053A 07). Lorena Zancada holds a Fellowship from the Consejería de Educación y Cultura de la Junta de Castilla y León. We acknowledge the generous collaboration of the Sociedad Cooperativa Ganadera de Lácteos y Derivados (Cogalad, Valderrodrigo, Salamanca, Spain) who kindly provided us with the samples. We are indebted to Angel García-Arroyo, a veterinary practitioner from Cogalad (Valderrodrigo, Salamanca, Spain). We are also grateful to N. Skinner (from the Servicio de Idiomas, Universidad de Salamanca, Spain) for revising the English version of the manuscript.

\section{REFERENCES}

Alais, C., and P. Jollès. 1967. Isolation, purification, and analysis of two K-casein-like fractions from sheep casein. J. Dairy Sci. 50:1555-1561.

Anifantakis, E.M. 1986. Comparison of the physico-chemical properties of ewes' and cows' milk. Pages 42-53 in IDF Bulletin no. 202 International Dairy Federation, Brussels, Belgium.

Bock, K., M. E. Breimer, A. Brignole, G. C. Hansson, K. A. Karlsson, G. Larson, H. Leffler, B. E. Samuelsson, N. Strömberg, C. Svanborg Edén, and J. Thurin. 1985. Specificity of binding of a strain of uropathogenic Escherichia coli to Gal $\alpha 1-4 \mathrm{Gal}-\mathrm{containing}$ glycosphingolipids. J. Biol. Chem. 260:8545-8551.

Christie, W. W., R. C. Noble, and G. Davies. 1987. Phospholipids in milk and dairy products. J. Soc. Dairy Technol. 40:10-12.

Dai, D., and W. A. Walker. 1999. Protective nutrients and bacterial colonization in the immature human gut. Adv. Pediatr. 46:353382.

Dewettinck, K., R. Rombaut, N. Thienpont, T. T. Le, K. Messens, and J. Van Camp. 2008. Nutritional and technological aspects of milk fat globule membrane material. Int. Dairy J. 18:436-457.

Dasgupta, S., E. L. Hogan, and S. S. Spicer. 1996. Stage-specific expression of fuco-neolacto- (Lewis X) and ganglio-series neutral glycosphingolipids during brain development: Characterization of 
Lewis $\mathrm{X}$ and related glycosphingolipids in bovine, human and rat brain. Glycoconj. J. 13:367-375.

Evans, D. G., and D. J. Evans. 1978. New surface-associated heat-labile colonization factor antigen (CFA/II) produced by enterotoxigenic Escherichia coli of serogroups O6 and O8. Infect. Immun. 21:638647.

Fauquant, C., V. Briard, N. Leconte, and M. C. Michalski. 2005. Differently sized native milk fat globules separated by microfiltration: Fatty acid composition of the milk fat globule membrane and triglyceride core. Eur. J. Lipid Sci. Technol. 107:80-86.

Fauquant, C., V. Briard-Brion, N. Leconte, M. Guichardant, and M. C. Michalski. 2007. Membrane phospholipids and sterols in microfiltered milk fat globules. Eur. J. Lipid Sci. Technol. 109:1167-1173.

Graves, E. L. F., A. D. Beaulieu, and J. D. Drackley. 2007. Factors affecting the concentration of sphingomyelin in bovine milk. J. Dairy Sci. 90:706-715.

Guineé, P. A., J. Veldkamp, and W. H. Jansen. 1977. Improved Minca medium for the detection of K99 antigen in calf enterotoxigenic strains of Escherichia coli. Infect. Immun. 15:676-678.8

IDF. 1996. Provisional standard 1D. Milk determination of fat content. Gravimetric method (reference method). International Dairy Federation, Brussels, Belgium.

Isaacs, C. E. 2005. Human milk inactivates pathogens individually, additively, and synergistically. J. Nutr. 135:1286-1288.

Karlsson, K. A. 1989. Animal glycosphingolipid as membrane attachment sites for bacteria. Annu. Rev. Biochem. 58:309-350.

Karlsson, K. A., and N. Stromberg. 1987. Overlay and solid-phase analysis of glycolipid receptors for bacteria and viruses. Methods Enzymol. 138:220-232.

Keenan, T. W., and S. Patton. 1995. Nature of the milk lipid globule membrane. Pages 5-20 in Handbook of Milk Composition. R. G. Jensen, ed. Academic Press Inc., New York, NY.

Keusch, J. J., S. M. Manzella, K. A. Nyame, R. D. Cummings, and J. N. Baenzinger. 2000. Cloning of Gb3 synthase, the key enzyme in globo-series glycosphingolipid synthesis, predicts a family of $\alpha 1-4$ glycosyltransferases conserved in plants, insects and mammals. J. Biol. Chem. 275:25315-25321.

Kiarash, A., B. Boyd, and C. A. Lingwood. 1994. Glycosphingolipid receptor function is modified by fatty acid content. J. Biol. Chem. 269:11138-11146.

Martín, M. J., S. Martín-Sosa, J. M. Alonso, and P. Hueso. 2003 Enterotoxigenic Escherichia coli strains bind bovine milk gangliosides in a ceramide-dependent process. Lipids 38:761768 .

Martín, M. J., S. Martín-Sosa, and P. Hueso. 2001. Bovine milk gangliosides: Changes in ceramide moiety with stage of lactation. Lipids 36:291-298.

Morrisey, P. A. 1973. The $N$-acetyl neuraminic acid content of the milk of various species. J. Dairy Res. 40:421-425.

Morrison, W. R., E. L. Jack, and L. M. Smith. 1965. Fatty acids of bovine milk glycolipids and phospholipids and their specific distribution in diacylglycerophospholipids. J. Am. Oil Chem. Soc. 42:1142-1147.

Newburg, D. S. 1996. Oligosaccharides and glycoconjugates in human milk: Their role in host defense. J. Mammary Gland Biol Neoplasia 1:271-283.

Newburg, D. S. 2005. Innate immunity and human milk. J. Nutr. 135:1308-1312.

Newburg, D. S., S. Ashkenazi, and T. G. Cleary. 1992. Human milk contains the Shiga toxin and Shiga-like toxin receptor glycolipid Gb3. J. Infect. Dis. 166:832-836.

Newburg, D. S., and P. Chaturvedi. 1992. Neutral glycolipids of human and bovine milk. Lipids 27:923-927.

Newburg, D. S., G. M. Ruiz-Palacios, and A. L. Morrow. 2005. Human milk glycans protect infants against enteric pathogens. Annu. Rev. Nutr. 25:37-58.

Puente, R., L. A. García-Pardo, R. Rueda, A. Gil, and P. Hueso. 1995 Ewes' milk: Changes in the contents of gangliosides and sialic acid during lactation. J. Dairy Res. 62:651-654.

Rosengren, B., J. E. Manson, and L. Svennerholm. 1987. Composition of gangliosides and neutral glycosphingolipids of brain in classical Tay-Sachs and Sandhoff disease: More lyso-GM2 in Sandhoff disease? J. Neurochem. 49:834-840.

Rueda, R. 2007. The role of dietary gangliosides on immunity and the prevention of infection. Br. J. Nutr. 98:568-573.

Sánchez-Juanes, F., J. M. Alonso, L. Zancada, and P. Hueso. 2009 Glycosphingolipids from bovine milk and milk fat globule membranes: A comparative study. Adhesion to enterotoxigenic Escherichia coli strains. Biol. Chem. 390:31-40.

Schweppe, C. H., M. Bielaszewska, G. Pohlentz, A. W. Friedrich, H. Büntemeyer, M. A. Schmidt, K. S. Kim, J. Peter-Katalinic, H. Karch, and J. Müthing. 2008. Glycosphingolipids in vascular endothelial cells: Relationship of heterogeneity in Gb3/CD77 receptor expression with differential Shiga toxin 1 cytotoxicity Glycoconj. J. 25:291-304

Sonnino, S., A. Prinetti, H. Nakayama, M. Yangida, I. Ogawa, and K. Iwabuchi. 2009. Role of very long chain fatty acid-containing glycosphingolipids in membrane organization and cell signalling: The model of lactosylceramide in neutrophils. Glycoconj. J. 26:615-621.

Teneberg, S., P. T. J. Willemsen, F. K. de Graaf, G. Stenhagen, W Pimlott, P. A. Jovall, J. Angström, and K. A. Karlsson. 1994 Characterization of gangliosides of epithelial cells of calf small intestine with special reference to receptor-active sequences for enterophatogenic Escherichia coli K99. J. Biochem. 116:560574.

Vesper, H., E. M. Schmelz, M. N. Nikolova-Karakashian, D. L. Dillehay, D. V. Lynch, and A. H. Merrill Jr.. 1999. Sphingolipids in food and the emerging importance of sphingolipids to nutrition. J. Nutr. 129:1239-1250.

Zaas, D. W., M. Duncan, J. R. Wright, and S. N. Abraham. 2005. The role of lipid rafts in the pathogenesis of bacterial infections. Biochim. Biophys. Acta 1746:305-313.)0 